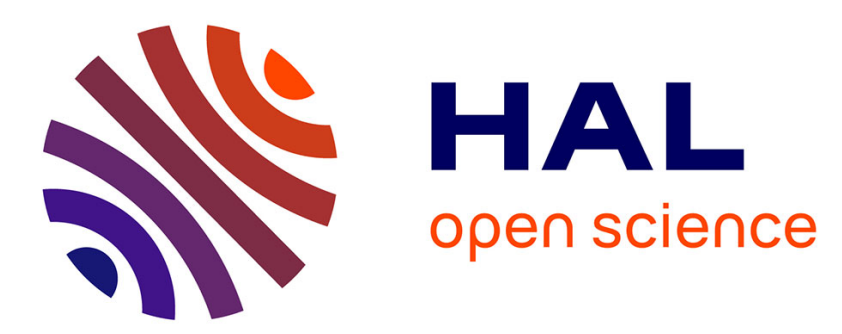

\title{
Effects of a reduction of working hours on a model with job creation and job destruction
}

Idoia Zabaleta, Dominguez Emilio, Miren Ullibarri

\section{To cite this version:}

Idoia Zabaleta, Dominguez Emilio, Miren Ullibarri. Effects of a reduction of working hours on a model with job creation and job destruction. Applied Economics, 2011, pp.1. 10.1080/00036846.2010.526583 . hal-00667596

\section{HAL Id: hal-00667596 https://hal.science/hal-00667596}

Submitted on 8 Feb 2012

HAL is a multi-disciplinary open access archive for the deposit and dissemination of scientific research documents, whether they are published or not. The documents may come from teaching and research institutions in France or abroad, or from public or private research centers.
L'archive ouverte pluridisciplinaire HAL, est destinée au dépôt et à la diffusion de documents scientifiques de niveau recherche, publiés ou non, émanant des établissements d'enseignement et de recherche français ou étrangers, des laboratoires publics ou privés. 


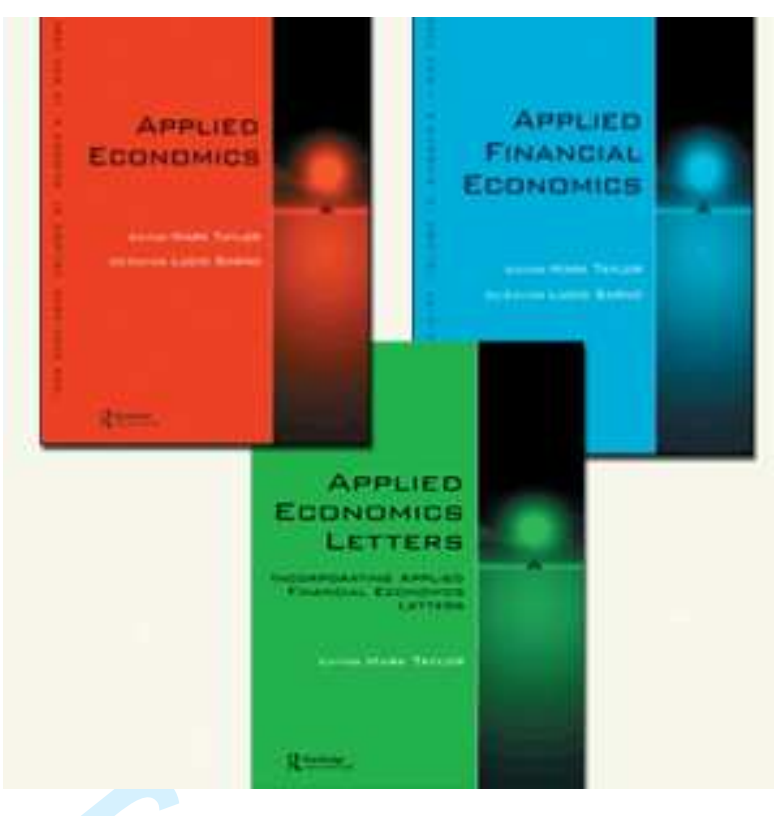

\section{Effects of a reduction of working hours on a model with job creation and job destruction}

\begin{tabular}{|r|l|}
\hline Journal: & Applied Economics \\
\hline Manuscript ID: & APE-2009-0105.R1 \\
\hline Journal Selection: & Applied Economics \\
\hline Date Submitted by the & 14-Sep-2010 \\
\hline Complete List of Authors: & $\begin{array}{l}\text { Zabaleta, Idoia; Public University of Navarra, Economicas } \\
\text { Emilio, Dominguez; Public University of Navarra, Economics } \\
\text { Ullibarri, Miren; Public University of Navarra, Economics }\end{array}$ \\
\hline JEL Code: & $\begin{array}{l}\text { D50 - General < D5 - General Equilibrium and Disequilibrium < D - } \\
\text { Microeconomics, J22 - Time Allocation and Labor Supply < J2 - } \\
\text { Time Allocation, Work Behavior, and Employment } \\
\text { Determination/Creation < J - Labor and Demographic Economics, } \\
\text { J41 - Contracts: Human Capital, Wage Models, Internal Labor } \\
\text { Markets < J4 - Particular Labor Markets < J - Labor and } \\
\text { Demographic Economics, J64 - Unemployment: Models, Duration, } \\
\text { Incidence, and Job Search < J6 - Mobility, Unemployment, and } \\
\text { Vacancies < J - Labor and Demographic Economics }\end{array}$ \\
\hline Keywords: & $\begin{array}{l}\text { General equilibrium, Tieme allocation and labour supply, matching } \\
\text { models, unemployment, vacancies }\end{array}$ \\
\hline & \\
\hline
\end{tabular}




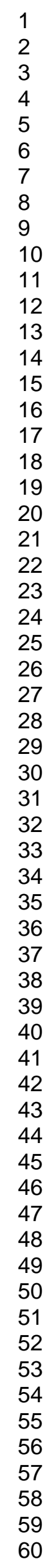

SCHOLARONE ${ }^{m}$
Manuscripts

25

26

27
28

29

30

32

33

34

35

36

37

38

40

41

42

44

45

46

47

48

49

51

52

54

55

57

58

59

60 
Figure 1. Percentage changes in the face of a reduction of working hours for different values of $\kappa$ with a non-separable utility function.

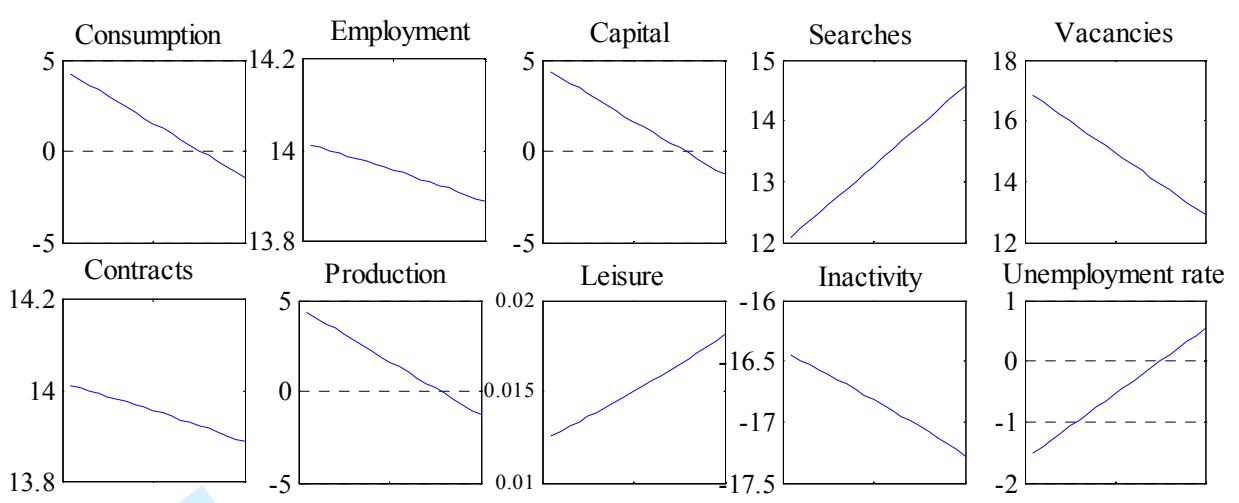

Note: The " $y$ " axis shows the units of variation of the variable, whilst the " $x$ " axis shows variation in the kappa values, ranging from 0.6 to 1 .

Results for the separable utility function are exactly the same. 
Figure 2: Dynamic of transition of the main variables with a non-separable utility function $\left(\kappa<\kappa^{*}, \kappa=0.85\right)$.
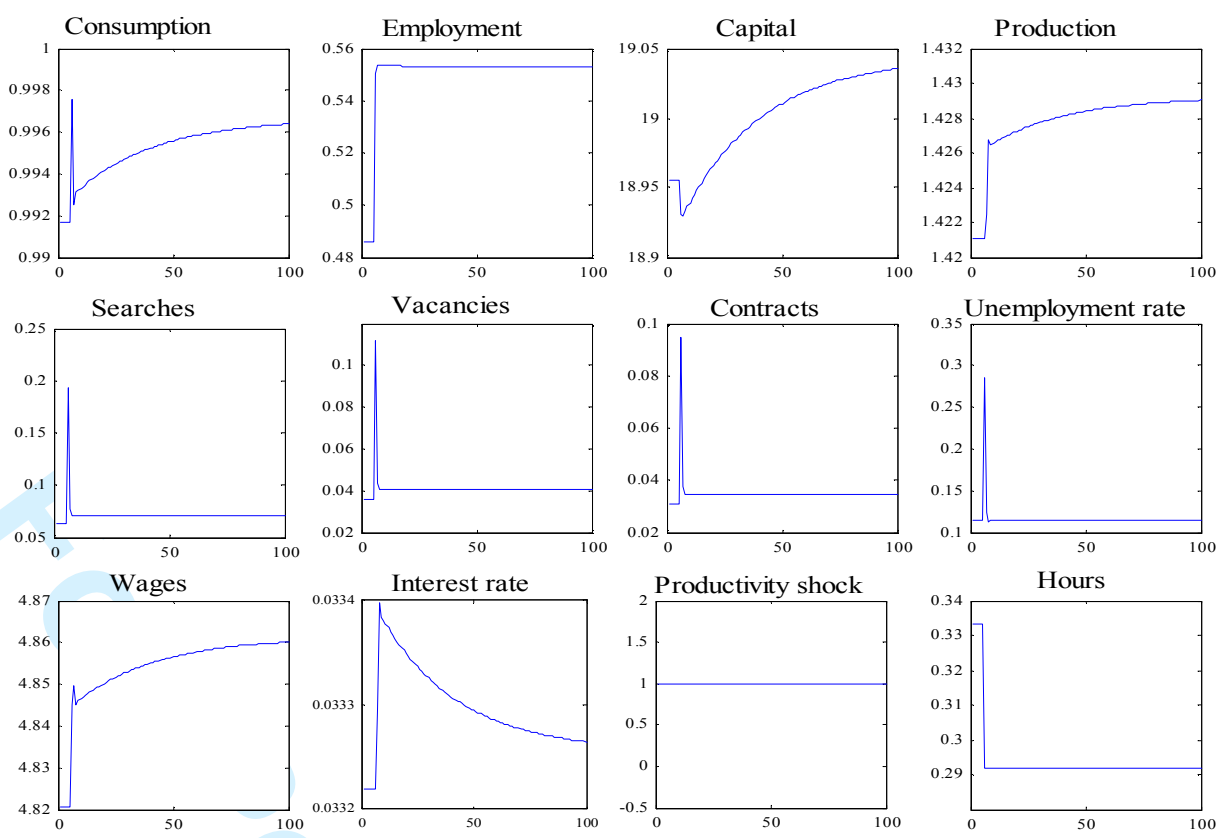
Figure 3: Dynamic of transition of the main variables with a non-separable utility function $\left(\kappa>\kappa^{*}, \kappa=0.9\right)$.
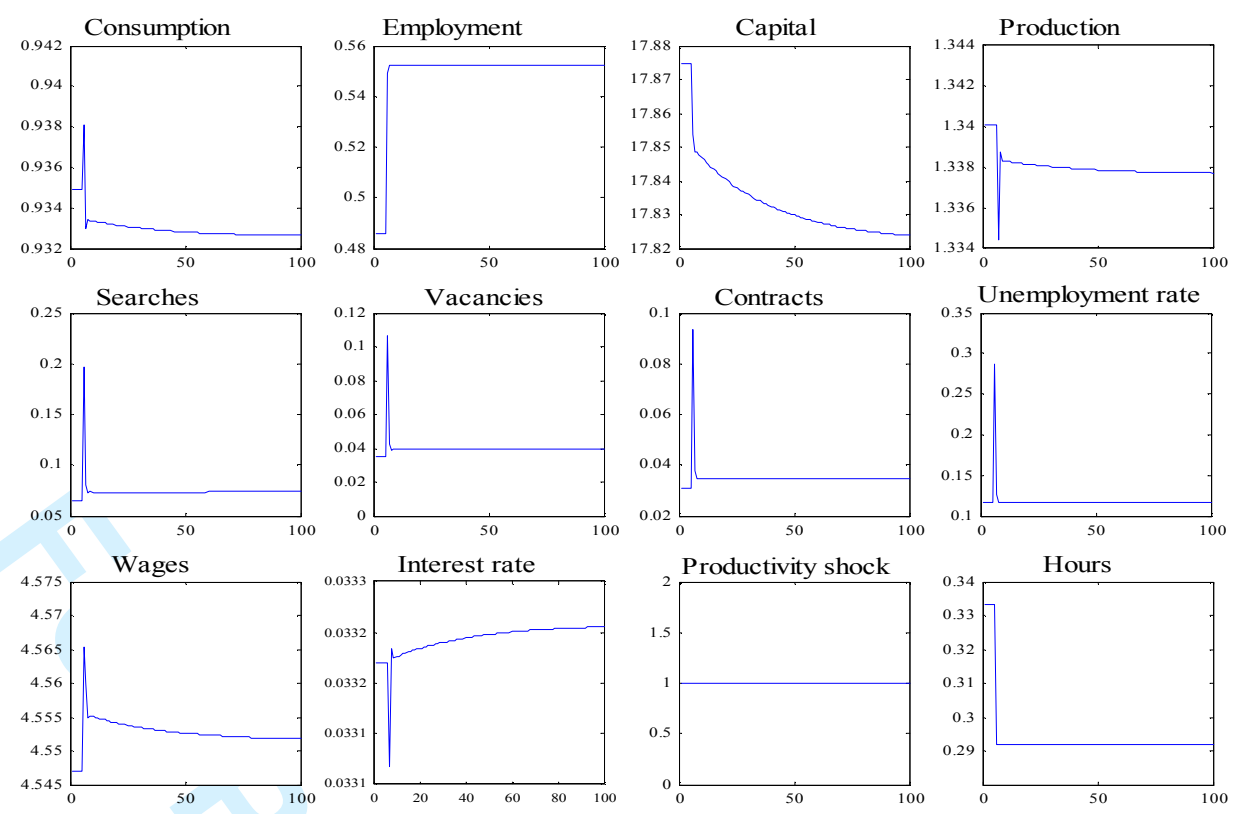

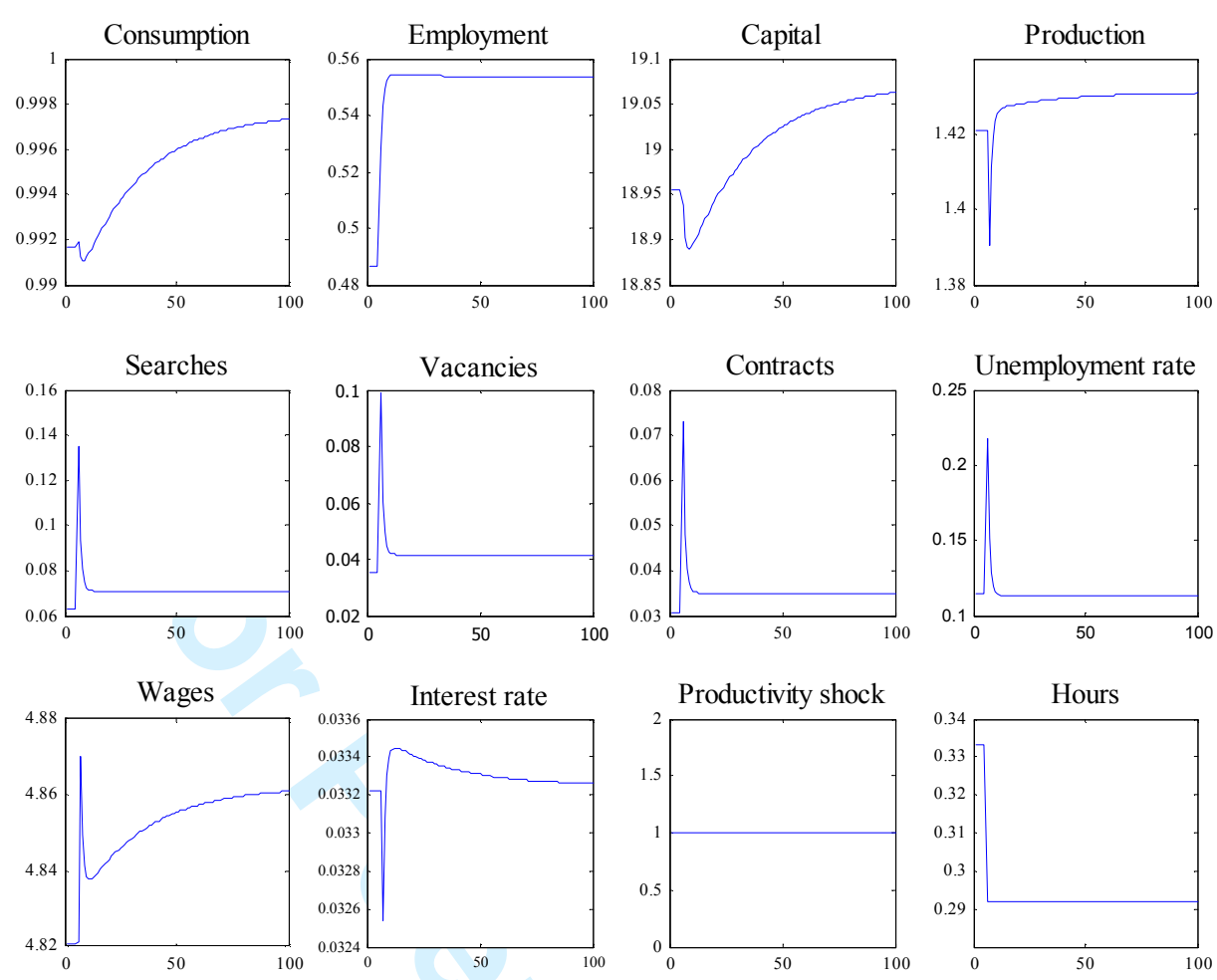
Figure 5: Dynamic of transition of the main variables with a separable utility function $\left(\kappa>\kappa^{*}, \kappa=0.9\right)$.
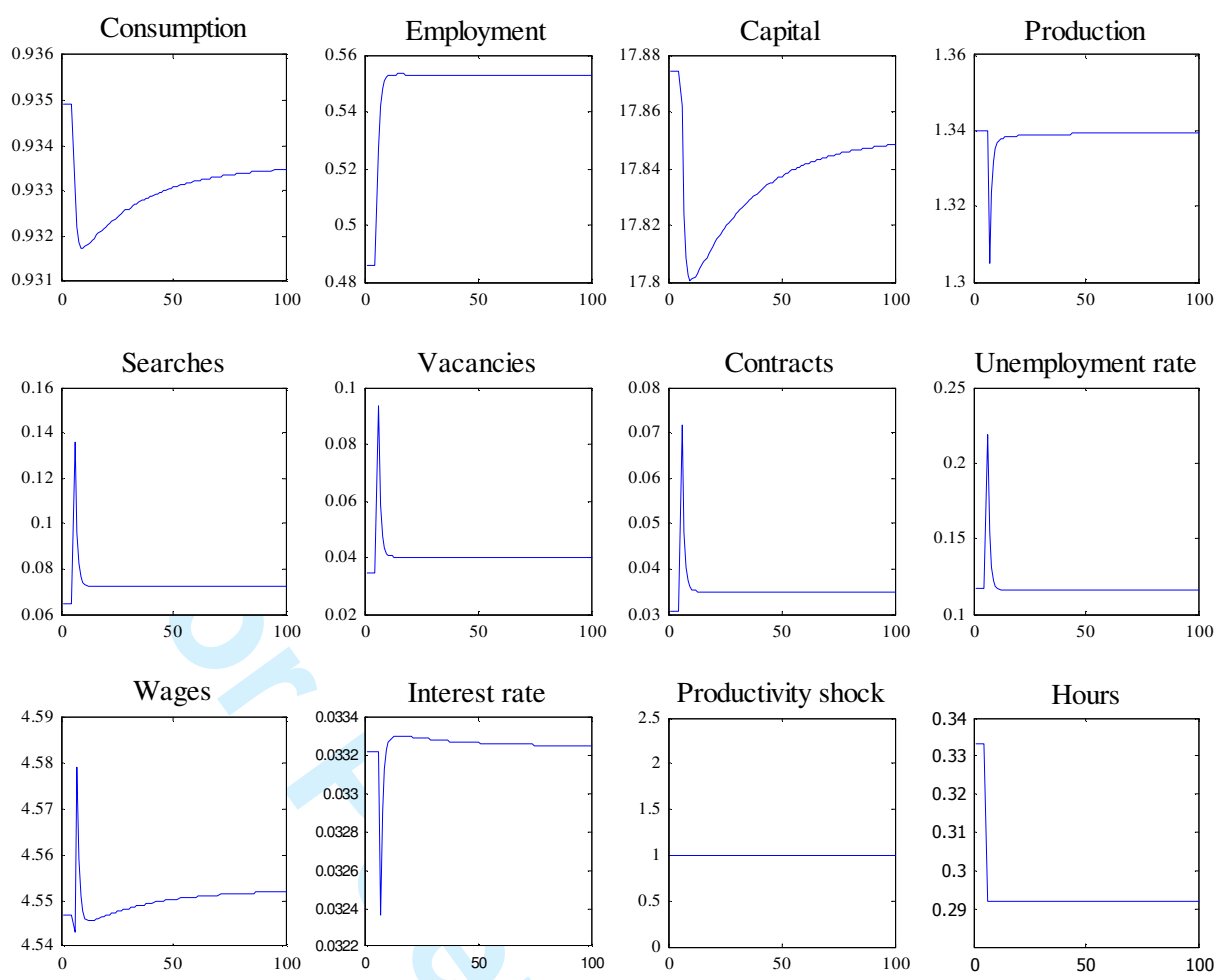

32

33

34

35

36 
Table 1: Calibration of the structural parameters

\begin{tabular}{|c|c|c|}
\hline Symbol & Value & Description \\
\hline \multicolumn{3}{|c|}{ Parameters of the utility function } \\
\hline$\gamma$ & -1.0 & Relative aversion to risk \\
\hline $\mathrm{b}$ & $1 / 24$ & Search time \\
\hline$\beta$ & 0.9891 & Subjective discount factor \\
\hline$\delta$ & 0.022 & Capital depreciation rate \\
\hline \multicolumn{3}{|c|}{ Non-separable utility function } \\
\hline$\alpha$ & 0.2006 & Elasticity of consumption \\
\hline \multicolumn{3}{|c|}{ Separable utility function } \\
\hline$\eta$ & 1.342 & Elasticity of the employment and search \\
\hline$\varpi_{n}$ & 8.89061 & Quasi-elasticity of the employment \\
\hline$\varpi_{B}$ & 36.14053 & Quasi-elasticity of search \\
\hline \multicolumn{3}{|c|}{ Parameters of the production function } \\
\hline$\varphi$ & 0.4431 & Elasticity of capital in the production function \\
\hline $\mathrm{h}$ & $8 / 24$ & Working hours \\
\hline$\kappa$ & 0.9 & Productivity of working hours \\
\hline $\mathrm{s}$ & 0.02 & Adjustment costs \\
\hline$\rho$ & 0.95 & Autoregressive productivity parameter \\
\hline \multicolumn{3}{|c|}{ Parameters related to job creation and job destruction } \\
\hline$\psi$ & 0.063 & Job destruction rate \\
\hline$\overline{\bar{m}}$ & 0.6146 & Scale parameter in the search function \\
\hline$\chi$ & 0.4108 & Elasticity of contracts \\
\hline $\mathrm{d}$ & 0.242 & Cost of vacancies \\
\hline
\end{tabular}


Table 4.1: Non-separable utility function

\begin{tabular}{lllllllll}
\hline & Volatility & $\mathbf{Y ( t - 3 )}$ & $\mathbf{Y ( t - 2 )}$ & $\mathbf{Y ( t - 1 )}$ & $\mathbf{Y ( t )}$ & $\mathbf{Y ( t + 1 )}$ & $\mathbf{Y ( t + 2 )}$ & $\mathbf{Y ( t + 3 )}$ \\
\hline $\boldsymbol{Y}$ & $1.46 \%$ & & & & & & & \\
\hline $\mathbf{c}$ & 0.33 & 0.43 & 0.60 & 0.81 & 0.95 & 0.71 & 0.36 & 0.11 \\
\hline $\mathbf{I}$ & 2.63 & 0.22 & 0.46 & 0.81 & 0.99 & 0.79 & 0.50 & 0.29 \\
\hline $\mathbf{n}$ & 0.61 & 0.27 & 0.53 & 0.92 & 0.86 & 0.57 & 0.36 & 0.20 \\
\hline $\mathbf{Y} / \boldsymbol{n}$ & 0.57 & 0.17 & 0.29 & 0.42 & 0.84 & 0.79 & 0.47 & 0.25 \\
\hline $\mathbf{u}$ & 7.50 & -0.24 & -0.32 & -0.46 & 0.06 & 0.32 & 0.23 & 0.18 \\
\hline
\end{tabular}

Standard deviation of innovation in productivity has been calibrated to reproduce variance in production as proposed by Puch and Licandro (1997), established as $1.46 \%$. All other values of the second column correspond to volatility ratios of the different variables on production. All series have been transformed logarithmically and filtered by Hodrick and Prescott's proposal for quarterly data. 
Table 3: Separable utility function

\begin{tabular}{|c|c|c|c|c|c|c|c|c|}
\hline & Volatility & $Y(t-3)$ & $Y(t-2)$ & $Y(t-1)$ & $Y(t)$ & $Y(t+1)$ & $Y(t+2)$ & $Y(t+3)$ \\
\hline$\underline{Y}$ & $1.46 \%$ & & & & 1.00 & 0.79 & 0.54 & 0.31 \\
\hline c & 0.28 & 0.49 & 0.62 & 0.76 & 0.91 & 0.64 & 0.34 & 0.09 \\
\hline I & 2.75 & 0.28 & 0.53 & 0.80 & 0.99 & 0.80 & 0.57 & 0.35 \\
\hline$\underline{\mathbf{n}}$ & 0.50 & 0.53 & 0.81 & 0.98 & 0.81 & 0.58 & 0.37 & 0.19 \\
\hline$\underline{Y} / \mathbf{n}$ & 0.66 & 0.08 & 0.22 & 0.46 & 0.90 & 0.76 & 0.55 & 0.34 \\
\hline$\underline{\mathbf{u}}$ & 3.41 & -0.49 & -0.51 & -0.34 & 0.28 & 0.37 & 0.36 & 0.32 \\
\hline
\end{tabular}




\title{
Effects of a reduction of working hours on a
}

\section{model with job creation and job destruction}

\author{
Emilio Domínguez, Miren Ullibarri, Idoya Zabaleta*
}

Department of Economics, Public University of Navarra, Campus Arrosadia, 31006

Pamplona, Navarra, Spain

\begin{abstract}
This paper shows how, with certain modifications to a standard real business cycle (RBC) model, and with certain qualified responses in the short and long term, a policy of reduction in the number of working hours can have positive effects on activity and employment. The modifications required to bring about these results include the specification of the working day, the existence of the creation and destruction of employment and a differentiation between inactivity and unemployment.
\end{abstract}

Results reveal that any measures taken to reduce the number of working hours must take into consideration the productivity levels of working hours, to thus ensure that the consequences of such a policy are positive not only for employment but also in all other macroeconomic variables.

JEL classification: D50; J22; J41; J64

Keywords: General equilibrium; Time allocation and labour supply; Matching Models; Unemployment; Vacancies

${ }^{*}$ Corresponding author. Tel.: +34-948-169339; fax: +34-948-169721. 


\section{Introduction}

In the course of the 1980's, high and persistent unemployment levels led governments to propose a reduction in working hours as a job creation policy. Decisions of this type have frequently been taken in times of recession, despite the fact that findings from empirical and theoretical studies differ on the capacity and validity of this type of policy to deliver the desired objective. This paper will propose a modified version of a general equilibrium model, including various aspects which have been forgotten or given secondary consideration over time but which appear necessary in this analysis.

Firstly, the category of inactive person is incorporated into the characterisation of the labour market. To date, most theoretical models on trends and variation in employment and unemployment have confined themselves to establishing a dichotomy between the employed and the unemployed. In this case, inactivity is added for the simple reason that the behaviour of the inactive population in relation to economic cycles does not correspond to that of the unemployed population (Tripier, 2003).

Merz (1995), one of the pioneers in the use of the category of inactivity, brings the inactive into focus by defining the variable of "search effort", such that the lower the level of effort, the higher the proportion of inactive people.

No theoretical studies on the policy of reducing the number of working hours take inactivity into account, despite this being a key aspect. More employment would not be, as is the case to date, synonymous of less unemployment if those

E-mail addresses: edominguez@unavarra.es (E. Domínguez), ullibarri@unavarra.es (M. 
who find work are drawn from the inactive population, attracted, for example, by shorter working days.

Secondly, a reduction in working hours may induce changes in labour productivity. In the course of a working day, workers' productivity decreases as a result of tiredness; thus, substituting less productive working hours for new workers could trigger an overall increase in the productivity of a working day.

Furthermore, a time period referred to as "adjustment costs" is established. This time period allows for the time required by each worker at the beginning of a working day to adapt to his/her job post, and may also be defined as the time required for the adjustment or start-up of machinery and computers, for checking that everything is correctly programmed, for assigning the work to be done, etc.

Thirdly, provision is made for the imbalance, or mismatch, between those looking for work and those offering work. This mismatch is brought about by the lack of comprehensive information on vacancies to be filled and/or the shortage of workers appropriately qualified to fill such vacancies in companies.

The most commonly used tool to reproduce any such market imbalance or mismatch is the aggregate matching function. This type of function began to appear in equilibrium models in the 1970's, though the idea underpinning these models with respect to market behaviour can be seen in previous studies. The validity of these and other economic functions lies in their empirical viability and their capacity to identify and grasp the consequences of market mismatches (Petrongolo and Pissarides, 2001).

However, this model-type has recently come into criticism on account of its inability to explain cyclical trends in unemployment, vacancies, trends and job

Ullibarri), idoia@unavarra.es (I. Zabaleta). 
reallocation rate (Shimer, 2005), as well as its shortcomings in reproducing the high volatility of some of these variables and the negative correlation between vacancies and unemployment (Yashiv, 2006) ${ }^{1}$.

This study recognises that these limitations are real. However, given that the objective of the study is not an in-depth analysis of the characterisation of these models, the study also makes full use of the advantages provided by the matching functions to study the consequences of a policy of reducing the number of working hours.

Some previous studies, such as Marimon and Zilibotti (2000), Contensou and Vranceanu (2000) and Rocheteau (2002), use matching functions to study the policy of reducing working hours, but differ in terms of their choice of reference economy, the specification of production and utility functions and the assumption of wage setting. Nevertheless, their conclusions coincide in their prediction of reduced production figures and expanded employment only under a series of very restrictive assumptions. This study differs from the previous studies in that it includes inactivity, decreasing productivity function in relation to the number of hours worked and not only analyses steady-state equilibrium but also the dynamics of the model. The analysis shows that the positive or negative effects of this policy on employment depend on the degree to which productivity increases as a result of the reduction in working hours, on whether adjustment costs are high or low and, of course, on the degree to which the inactive population are attracted by the idea of a shorter working day.

Section 2 of this paper defines the model and study methodology, section 3 deals with the calibration and origin of the numerical information cited, section 4

\footnotetext{
${ }^{1}$ Yashiv (2007) develops a model which produces a better adjustment of data and a more realistic behaviour of macroeconomic variables.
} 
outlines the main results of the study and section 5 addresses the conclusions drawn.

\section{The model}

\subsection{The matching function}

A Cobb-Douglas function with homogeneity of degree one can be supposed, such that:

$$
m_{t}=\bar{m} v_{t}^{\chi} B_{t}^{1-\chi}
$$

whereby $v_{t}$ represents the vacancy rate and $B_{t}$ the search rate, both in respect of the total population. Additionally, $\bar{m}$ represents efficiency of adjustment, also referred to as scale factor, $\chi$ the elasticity of contracts and $m_{t}$ represents the job reallocation rate. The subscript $t$ indicates time. The chosen matching function has constant returns to scale, as that used by Blanchard and Diamond (1989) for data on the American economy and that used by Pissarides (1986) for data on the United Kingdom.

On the basis of this function, labour market rigidity is expressed as: $\theta_{t}=v_{t} / B_{t}$. The probability of a job vacancy being occupied is the same as: $q_{t}=m_{t} / v_{t}$ and the probability of an unemployed person finding work is expressed as: $p_{t}=\theta_{t} q_{t}$. 
Each period of time produces a particular job destruction rate $\psi$, such that work (expressed as $n_{t}$ ) in each period of time follows a dynamic process in line with the equation below:

$$
n_{t+1}=(1-\psi) n_{t}+m_{t}
$$

\subsection{Households}

Following the proposal of Tripier (2003) an endogenous participation function is used. Thus, the utility function of any given representative household depends on consumption of the only available good in the economy $c_{t}$ and leisure $o_{t}$. The members of the household, are divided up into three possible activity groups, i.e. employed, unemployed and inactive.

The utility function is defined as:

$$
U_{t}=U\left(c_{t}, l_{t}, B_{t}, n_{t}\right)
$$

In this function, $l_{t}$ represents the inactive proportion of the household in relation to the total population, $B_{t}$ represents the unemployed and $n_{t}$ the employed. The size of the households is standardised as 1 , such that: $1=l_{t}+B_{t}+n_{t}$.

Consumers are owners of the total work force, capital (k) and companies. They obtain resources ( $\mathrm{w}_{\mathrm{t}}$ is the salary and $\mathrm{r}_{\mathrm{t}}$ is the capital return) which finance consumption $\left(\mathrm{c}_{\mathrm{t}}\right)$ and investment $\left(\mathrm{I}_{\mathrm{t}}\right)$, by hiring out those productive factors to companies and from their profits $\left(\pi_{t}\right)$. Furthermore, in each given period of time, consumers are faced with the decision to invest in capital, influenced in turn by 
capital depreciation $(\delta)$. Hours spent working are represented by $\mathrm{h}_{\mathrm{t}}$. Finally, they are bound by the dynamic of employment. Thus, households are faced with the following problem of maximisation:

$$
\begin{gathered}
\operatorname{Max} E_{0} \sum_{t=1}^{\infty} \beta^{t} U_{t}=U\left(c_{t}, l_{t}, B_{t}, n_{t}\right) \\
\text { subject to } \quad c_{t}+I_{t}=w_{t} n_{t} h_{t}+r_{t} k_{t-1}+\pi_{t} \\
k_{t}=(1-\delta) k_{t-1}+I_{t} \\
n_{t+1}=(1-\psi) n_{t}+p_{t} B_{t}
\end{gathered}
$$

and supposing $k_{t-1}$ and $n_{0}$

Analysis is conducted using two different specifications of the utility function, separable and non-separable, with a view to checking the degree of consistency or stability of the results. The non-separable function resembles the proposal put forward by Kydland and Prescott (1982):

$$
U_{t}=\frac{\left[c_{t}^{\alpha}\left(1-h_{t} n_{t}-b B_{t}\right)^{1-\alpha}\right]^{\gamma}-1}{\gamma}
$$

where $\alpha>0$ y $\gamma<0$.

This function includes consumption $\mathrm{c}_{\mathrm{t}}$ and leisure $\mathrm{o}_{\mathrm{t}}$ as arguments, where $\alpha$ is the proportion of time spent on obtaining income for consumption and (1- $\alpha)$ is the proportion of time spent on leisure. The degree of relative aversion to risk is $\gamma \in[1,-\infty]$, whilst the parameter $\mathrm{b}$ reflects time dedicated to looking for work. Work 
is indivisible to ensure a convex ${ }^{2}$ set of consumption possibilities. The time available to each worker is standard and unitary, so leisure in the aggregate utility function can be expressed as: $\mathrm{o}_{\mathrm{t}}=1-\mathrm{h}_{\mathrm{t}} \mathrm{n}_{\mathrm{t}}-\mathrm{b} B_{t}{ }^{3}$.

As stated above, the economy is made up of identical consumers. Furthermore, a standardised population is supposed, such that if all players worked, $n$ (proportion of workers) would take on the value 1 and total leisure would be equal to $1-\mathrm{h}_{\mathrm{t}}$

The separable utility function is derived from the labour hypothesis of Hornstein and Yuan (1998):

$$
\begin{aligned}
& U_{t}=\ln c_{t}-\varpi_{B} \frac{B_{t}{ }^{\eta} b^{\eta}}{\eta}-\varpi_{n} \frac{n_{t}^{\eta} h_{t}^{\eta}}{\eta} \\
& \text { where } \varpi_{B}>0, \varpi_{n}>0 \text { у } \eta>1 .
\end{aligned}
$$

2 That is to say, the individuals of all households are restricted in their possible working days. They either work the whole day or they don't, i.e. they cannot work odd hours or accumulate hours to make up a whole day if, for example, in a family of two individuals, each one works a half day (Hansen, 1985 and Rogerson, 1988).

${ }^{3}$ Definitions:

$\mathrm{H}_{\mathrm{Nt}}$ : Hours worked by the employed

$\mathrm{H}_{\mathrm{P}}$ : Hours spent by the unemployed on looking for work

$\mathrm{H}_{\mathrm{Lt}}$ : Total hours available

$\mathrm{N}_{\mathrm{t}}$ : Employed

$\mathrm{P}_{\mathrm{t}}$ : Unemployed.

$S_{\mathrm{t}}$ : Inactive people

Total population: $\mathrm{L}_{\mathrm{t}}=\mathrm{N}_{\mathrm{t}}+\mathrm{P}_{\mathrm{t}}+S_{\mathrm{t}}$

$\mathrm{H}_{\mathrm{Nt}} \mathrm{N}_{\mathrm{t}}+\left(\mathrm{H}_{\mathrm{Lt}}-\mathrm{H}_{\mathrm{Nt}}\right) \mathrm{N}_{\mathrm{t}}+\mathrm{H}_{\mathrm{Pt}} \mathrm{P}_{\mathrm{t}}+\left(\mathrm{H}_{\mathrm{Lt}}-\mathrm{H}_{\mathrm{Pt}}\right) \mathrm{P}_{\mathrm{t}}+\mathrm{H}_{\mathrm{L}} \mathrm{S}_{\mathrm{t}}=\mathrm{H}_{\mathrm{Lt}} \mathrm{L}_{\mathrm{t}}$

Leisure is defined as: $\left(\mathrm{H}_{\mathrm{Lt}}-\mathrm{H}_{\mathrm{Nt}}\right) \mathrm{N}_{\mathrm{t}}+\left(\mathrm{H}_{\mathrm{Lt}}-\mathrm{H}_{\mathrm{Pt}}\right) \mathrm{P}_{\mathrm{t}}+\mathrm{H}_{\mathrm{Lt}} \mathrm{S}_{\mathrm{t}}=\mathrm{H}_{\mathrm{Lt}} \mathrm{L}_{\mathrm{t}}-\mathrm{H}_{\mathrm{Nt}} \mathrm{N}_{\mathrm{t}}-\mathrm{H}_{\mathrm{Pt}} \mathrm{P}_{\mathrm{t}}$

Dividing by $\mathrm{H}_{\mathrm{L}} \mathrm{L}_{\mathrm{t}}$ leisure is obtained in the same way as $\mathrm{h}_{\mathrm{t}}, \mathrm{n}_{\mathrm{t}}, \mathrm{b}$ and $\mathrm{B}_{\mathrm{t}}$ are defined in this study:

Leisure $\equiv 1-\frac{\mathrm{H}_{\mathrm{Nt}}}{\mathrm{H}_{\mathrm{Lt}}} \frac{\mathrm{N}_{\mathrm{t}}}{\mathrm{L}_{\mathrm{t}}}-\frac{\mathrm{H}_{\mathrm{Pt}}}{\mathrm{H}_{\mathrm{Lt}}} \frac{\mathrm{P}_{\mathrm{t}}}{\mathrm{L}_{\mathrm{t}}} \equiv 1-\mathrm{h}_{\mathrm{t}} \mathrm{n}_{\mathrm{t}}-\mathrm{bB}_{\mathrm{t}}$ 
Here, $\eta$ is the elasticity of employment and search, $\varpi_{B}$ reflects a loss of satisfaction due to looking for work and $\varpi_{n}$, on the other hand, represents dissatisfaction from working.

\subsection{Companies}

It is assumed that all companies are identical and competing in conditions of perfect competition. To produce the only good in the economy $\left(\mathrm{Y}_{\mathrm{t}}\right)$, companies use a combination of capital and work, as defined in the following Cobb-Douglas function:

$$
Y_{t}=A k_{t-1}^{\varphi}\left(n_{t}\left(h_{t}-s\right)^{\kappa}\right)^{1-\varphi}
$$

In this function, $A$ represents technical progress and shows the position of the isoquant (technical progress only influencing $A$ may be described in terms of a shift in the position of the isoquant). It is used to introduce technological shock.

The capital used is the capital stock of the economy at the beginning of each period, with no friction or adjustment costs involved in its incorporation. Companies hire the capital they need from householders. Thus, the cost of capital is expressed as $r_{t} k_{t-1}$.

Work is represented as the aggregate product of employment $\left(n_{t}\right)$, a differenciable and strictly concave function of working hours: $g(h)=(h-s)^{\kappa}$ $\left(g^{\prime}(h)>0\right.$ and $g^{\prime \prime}(h)<0$, where productivity is represented by $\kappa \in[0,1]$ and $s$ covers, in terms of working time, those adjustment costs attributable to adaptation to the work post and the adjustment or start-up of machinery. 
The specification of work in production technology resembles that used by Osuna and Ríos-Rull (2003), whereby productivity of working hours, represented as $\kappa$ in our model, is a key element of analysis. These writers observe how a reduction of working hours, provoked in their case by overtime taxation, increases employment, but only at the expense of a decrease in production and productivity.

Output elasticity in relation to capital and work corresponds to $\varphi$ and $1-\varphi$, where $0<\varphi<1$.

Companies also decide on the number of vacancies, which will not be completely filled in each period of time. The probability of filling a vacancy is represented as $q_{t}$. There are also a series of costs (job advertising, selection costs), referred to as $d$, derived from the existence of vacancies.

Thus, companies are faced with the following problem of maximisation:

$$
\pi_{t}=\underset{k_{t}, v_{t}}{\operatorname{Max}}\left\{Y_{t}-w_{t} n_{t} h_{t}-r_{t} k_{t-1}-d_{t} v_{t}\right\}
$$

subject to

$$
n_{t+1}=(1-\psi) n_{t}+q_{t} v_{t}
$$

and supposing $k_{t-1}$ and $n_{0}$

\subsection{Planner's solution}

As in real business cycle (RBC) models, the planner's solution is used. Hosios (1990), Merz (1995) and Yashiv (2007) put forward a wage bargaining scenario, which reproduced the planner's solution in competitive equilibrium. The model brings to light two externalities; the first, those people looking for work, and the 
second, the companies needing to fill vacancies. A scenario in which many people are looking for work is convenient for companies, as they will therefore be in a better position to fill their vacancies. Conversely, this is detrimental for those looking for work as they face greater competition. The best scenario for those looking for work is for there to be many vacancies; for companies, however, such a scenario represents expensive labour and unfilled vacancies. Thus, salary functions will occur in which all these external factors are compensated, and it is then when competitive equilibrium and the planner's solution coincide. This paper will describe the simpler planner's situation.

The planner solves the problem of maximisation of the consumer subject to a global economic budgetary restriction, where both consumer and company restrictions are standardised. Additionally, the planner takes into account the laws of capital accumulation, the labour market dynamic and the matching function ${ }^{4}$. The first order conditions derived from resolving the problem, having established the value of the multipliers, are as follows:

$$
\begin{aligned}
& d_{t} U_{t}^{c}=-\frac{\partial m_{t}}{\partial v_{t}}\left(\frac{\partial m_{t}}{\partial B_{t}}\right)^{-1} U_{t}^{B} \\
& \left.U_{t}^{c}=\beta E_{t} \mid\left((1-\delta)+F_{t+1}^{k}\right) U_{t+1}^{c}\right] \\
& d_{t}\left(\frac{\partial m_{t}}{\partial B_{t}}\right)^{-1} U_{t}^{c}=\beta E_{t}\left[\left(F_{t+1}^{n}+(1-\varphi) d\left(\frac{\partial m_{t+1}}{\partial B_{t+1}}\right)^{-1}\right) U_{t+1}^{c}\right]+\beta E_{t}\left[U_{t+1}^{n}\right] \\
& c_{t}+I_{t}=A k_{t-1}^{\varphi}\left[n_{t}\left(h-s^{\kappa}\right)\right]^{1-\varphi}-d_{t} v_{t} \\
& k_{t}=(1-\delta) k_{t-1}+I_{t} \\
& n_{t+1}=(1-\psi) n_{t}+m_{t}
\end{aligned}
$$




$$
\begin{aligned}
& m_{t}=\bar{m} v_{t}^{\chi} B_{t}^{1-\chi} \\
& A_{t}=\rho A_{t-1}+\varepsilon_{t}
\end{aligned}
$$

A transversality condition must be imposed to avoid explosive solutions, thus ruling out the possibility of obtaining a corner solution:

$$
\lim _{\tau \longrightarrow \infty} E_{t}\left|\beta^{\tau} k_{t+\tau} u_{t+\tau}^{c}\right|=0
$$

Return on capital and on workers' salary/ hour is calculated by using a strategy of competitive equilibrium which mimic the same allocations of use and resources as the planner.

\section{Calibration}

Table 3.1 shows the value assigned to each parameter to reproduce the characteristics of the Spanish economy in the steady state. Whilst certain parameter values are taken from published studies, the rest are obtained through calibrating the model such that, in the steady state, the same values are obtained as in the real economy for structural variables (investment ratios on production, activity and unemployment rates, etc.). The calibration of the parameters of the most relevant functions is described in detail below.

\footnotetext{
${ }^{4}$ For details of the numerical solution, please contact authors.
} 


\subsection{Parameters of the utility function}

The discount factor, one of the most frequently found, is assigned a value of 0.9891 from the work of Puch and Licandro (1997) for the Spanish economy. However, this practically coincides with the value used by Merz (1995), Cotensou and Vranceanu (2000), Den Haan et al. (2000) etc.

Quasi-elasticity (with respect to consumption) of the non-separable utility function, $\alpha$, is calibrated in such a way as to reproduce, in a steady state, the inactivity rate of the Spanish economy for the period 2000-2003, obtained from the Labour Force Survey (LFS) of the Spanish Statistical Institute.

Also with regard to the non-separable utility function, the time dedicated to looking for work, $b$, is established as 1 hour, in line with the studies of Layard et al. (1994) (with information relative to Great Britain for the period 1978-79) and Greenwood et al. (1996) (data from the United States for the year 1979) ${ }^{5}$.

For the separable function, elasticity with respect to work $\eta$ and to unemployment is taken from Tripier (2003). Dissatisfaction caused by unemployment and employment, $\varpi_{B}$ and $\varpi_{n}$ respectively, is calibrated in the model. Firstly, the problem with the non-separable function is resolved, and from thereon, for a given value of $\alpha$, values for $\varpi_{B}$ and $\varpi_{n}$ are calculated such that the resultant values for the steady state and those of the approach with a nonseparable function are the same ${ }^{6}$.

\footnotetext{
${ }^{5}$ The dated nature of the information used here, and the fact that it relates to other countries, is due to the impossibility of finding more adequate data in both time and geographical terms.

${ }^{6}$ Values used by Tripier (2003) for the $\varpi_{n}$ and $\varpi_{B}$ parameters are 1.614 and 0.657 respectively. A quantitatively significant difference is observed between the values used in this model and those given by the writer. This is attributable to the difference between the definition of these parameters in the model proposed in this study and that of Tripier (2003):
} 


\subsection{Parameters of the production function}

Elasticity of capital is calibrated within the model in such a way as to reproduce the proportions of consumption and capital of the Spanish economy (Puch and Licandro, 1997). The value derived is similar to that of 0.4 used by Andrés et al. (2006) in their study of price rigidity and the volatility of vacancies and unemployment in matching models. Other writers such as Merz (1995) and Den Haan et al. (2000) assign a value of 0.36, whilst Tripier (2003) establishes a value of 0.35 .

A common parameter is that of capital depreciation, for which the value of 0.022 used by Merz (1995) has been established. In their study with a search model, Mortensen and Pissarides (1994) use a value of 0.01, whilst Den Haan et al. (2000) uses 0.025 and Tripier (2003) uses 0.015. Table 1 lists the values used in calibration.

\section{[ Insert here table 1 ]}

The value for the cost incurred by employers in having job posts available $d$ is taken from Tripier (2003). This value is also similar to that of 0.213 obtained by Andrés et al. (2006). Productivity shock is represented through a first order autoregressive, with unitary expectation and a value of 0.95 for the autoregressive

\footnotetext{
$\varpi_{n}$ corresponds approximately in this study to: $\varpi_{n} h^{\eta}$

$\varpi_{B}$ corresponds approximately in this study to: $\varpi_{B} b^{\eta}$
} 
parameter $(\rho)$. This is the same value as that used in the studies of Cole and Rogerson (1999) and Tripier (2003).

\subsection{Parameters related to job creation and destruction}

Studies on job destruction rate have been conducted for the Spanish economy, e.g. García (1997), Dolado et al. (1997) and Antolín (1997). With respect to a value for the job destruction rate of the model, it was decided to assign that of Tripier $^{7}$ (2003), established at $\psi=0.063$ and very close to the average of those assigned by Spanish writers ${ }^{8}$.

Additionally, the activity and unemployment rates $(53.87 \%$ and $11.77 \%$, respectively) correspond to the average value of these rates for the Spanish economy for the period 2000-2003. Both the elasticity of the job reallocation rate with respect to unemployment and vacancies, standing at $\chi$ and $(1-\chi)$ respectively ${ }^{9}$, and $\bar{m}$ are calibrated in the model to reproduce the unemployment rate.

For hiring costs $d$, the model uses the value of 0.242 established by Tripier (2003), which coincides with that of 0.25 used in the studies of Contensou and Vranceanu (2000) and 0.203 used by Den Haan et al. (2000).

\footnotetext{
${ }^{7}$ This writer simulates the economy for the United States.

${ }^{8}$ García (1997) assigns exit rates from employment ranging from around $3 \%$ to $12 \%$, depending on workers' qualifications, age, etc.

Dolado et al. (1997) give a reference value for job destruction of around 2-3\% for SMEs $(<500$ employees) in Spain, and of 9-10\% for large size companies (> 500 employees).

${ }^{9}$ With respect to the parameter $\chi$, a Spanish study by Castillo et al. (1998) assigns the value of 0.15 , in contrast with other values assigned in studies for this same parameter by Burda (1994), within an interval of 0.5-0.7, Mortensen and Pissarides (1994), with a value of 0.5, etc.
} 


\section{Results}

Analysis of the predictions of the model with respect to a reduction of working hours reveals that the implications of such a policy are sensitive to the value of the parameter $\kappa$, which determines the productivity of working hours.

This has conditioned the presentation of the results of the study. Thus, after a brief analysis of the cyclical behaviour of this economy, results will be focused on an analysis of the policy of a reduction of working hours. This analysis will begin with an assessment of the effects on steady state values, together with the sensitivity analysis of these effects for different values of $\kappa$. Short-term effects will then be analysed through studying the dynamic of transition between those steady states corresponding to different values for the duration of the working day. In this case, results for different values of $\kappa$ are also presented.

Finally, although two utility function specifications have been used (separable and non-separable), it has been observed that this difference has minimum effect on results. Thus, results are generally presented with reference to the nonseparable utility function, and specific comments will only be made with respect to the separable utility function when considered relevant.

\subsection{Cyclical properties}

To analyse the cyclical properties of this economy, 100 simulations have been conducted with 100 observations per simulation. For each simulation, calculation has been made of standard deviations and the correlations between resolved 
variables and others established on the basis of that information, such as production (Y) and investment (I).

The following tables show sample averages of statistics on volatility and the correlations between relevant variables, those on which data are available through Puch and Licandro (1997) for the Spanish economy and those of interest in other studies (Merz-1995, Tripier-2003, amongst others) on the labour market.

\section{[ Insert here table 2 ]}

\section{[ Insert here table 3 ]}

The statistics shown in Tables 2 and 3 are qualitatively similar to those observed for the Spanish economy, as described in Puch and Licandro (1997), though certain differences can be observed on a quantitative basis. The cyclical properties of unemployment are not perfectly aligned to the behaviour observed in real economies. This defect of models of job creation and destruction has been documented in literature on the subject matter, amongst others by Tripier (2003).

In short, these results are similar to those obtained in other studies in which simple models of general equilibrium are developed, such as Puch and Licandro (1997), Merz (1995) and Tripier (2003).

\subsection{Steady state}

Appendix 1 shows percentage changes, for a collection of activity and labour market variables, produced in a steady state when working hours are reduced from 40 to 35 per week. These changes have been calculated for a set of values of the 
parameter $\kappa$ in the interval $[0.6 ; 1]$. In some cases, the responses of the variables to the reduction of working time change sign (from positive to negative). Hereinafter, the value of $\kappa$ defined by this behavioural change will be referred to as the boundary value and represented as $\kappa^{*}$. With the previously described calibration, the value of $\kappa^{*}$ is equal to $0.95^{10}$. The main results obtained in this analysis are outlined below.

Employment variation is dependent on the productivity of working hours. As the number of working hours decreases, employment always increases. However, the higher the productivity level of working hours and the greater the adjustment costs, the lower the growth rate (see Appendix 1, Figure 1).

Reducing the number of working hours increases or reduces capital, production and consumption, depending on the value assigned to productivity $\kappa$. If this value is below the boundary value $\kappa^{*}$, the three values increase, and the lower the values of $\kappa$ and/or the adjustment costs, the greater this increase will be. If the value exceeds the boundary value $\kappa^{*}$, the opposite will occur. The point at which conclusions change is different for these three variables.

The unemployment rate decreases in response to a growth in employment, though this decrease flattens out as $\kappa$ increases (and as growth in employment diminishes). From a certain point onwards unemployment begins to increase, despite the fact that employment continues to be created. This is attributable to a fraction of the inactive population becoming active, a part of which is not absorbed by the labour market.

The increase in the active population caused by the policy of a reduction of working hours shows a positive relation with $\kappa$. Firstly, as $\kappa$ increases, available

\footnotetext{
${ }^{10}$ For example, the value is inversely dependent on the value assigned to adjustment costs on working time.
} 
leisure in the economy becomes greater (leisure is equal to $1-\mathrm{hn}_{\mathrm{t}}-\mathrm{bB}_{\mathrm{t}}$ ), so its marginal utility decreases. As leisure is more available, the time dedicated to looking for work becomes relatively cheaper, so the number of people looking for work will increase, as will activity.

Vacancies, which increase in any case, maintain an inverse relation with $\kappa$ and with adjustment costs, which may be attributable to twin causes. On one hand, good expectations regarding employment may encourage companies to offer more jobs, though this attitude would abate as the growth in employment slows down. On the other hand, though linked to the previous scenario, the more favourable situation in terms of consumption and production, when the value of $\kappa$ is low, may provide the incentive for more resources to be assigned to offering vacant job posts.

Contracts follow the same pattern as vacancies, though not in such an intense manner. As can be seen in the graphs, the resultant curve for contracts is less steep, attributable to the fact that growth rates for search are increasing in $\kappa$. Employment mimics behaviour of contracts.

Finally, the behaviour trend of unemployment and vacancies coincides with the predictions of the Beveridge ${ }^{11}$ curve only for values of $\kappa<\kappa^{*}$. Tripier (2003) observes a direct relation between these two variables when confronted with a positive production shock. Greater production not only brings about an increase in the offer of vacancies, but also in the active population. One part of this

\footnotetext{
11 One of the applications derived from these functions is that known as the Beveridge curve. This curve, obtained from aggregate information on unemployment stocks and vacancies, represents the relation between unemployment rates and vacancies in a steady state, a situation in which unemployment remains stable as its inflows and outflows are equal. The curve reflects the inverse relation between the vacancy rate and the unemployment rate, and is a useful tool for analysing the effects of structural changes on labour markets. Dolado and Gómez (1997) study the relation between unemployment and job vacancies in Spain, identifying factors which explain the dynamic of unemployment over the period 1977-94.
} 
population remains unemployed, so more vacancies coincide with more unemployment. This is so when $\kappa>\kappa^{*}$.

\subsection{Transition dynamic}

Analysis of the transition dynamic between two steady states is used to discuss the short-term effects of the reduction in working hours. This is done on the basis of long-term equilibrium values for a 40-hour working week and allowing the model to evolve dynamically with no productivity shocks. A change in the value of the working week is introduced in the sixth period, from 40 to 35 hours, allowing the model once again to evolve towards the new steady state value. As in the previous analysis, the effects of the policy of a reduction of working hours on the variables of activity and the labour market are crucially depend on the value assigned to $\kappa$, so this analysis is conducted for two different calibrations of this parameter, i.e. one below and one above the boundary value established in the previous section.

\subsubsection{Dynamic of transition supposing $\kappa<\kappa^{*}$}

The policy of a reduction of working hours always leads to increases in employment (see Appendix 2, Figures 2 and 4).

The explanation behind this statement can be found in the increased productivity brought about by eliminating hours of low productivity and, especially, by replacing hours with workers. 
The reduction of working hours produces an increase in capital, production and consumption.

Capital, maintained at a constant level during the first period, is used more intensively, thus triggering an increase in interest rate which will level off in future periods in response to a subsequent increase of capital. More capital and employment both contribute to a boost in production and consumption. However, the level of capital goes down slightly in the second period before starting to rise again, as mentioned above. This reduction is due, as will be seen later, to companies putting vacancies on the market in the first period, the cost of which is covered at the expense of funds earmarked for investment or consumption (in this particular case, investment). As vacancies go down in the second period, and with them the funds assigned to them, capital begins its upward trend.

In the case of the separable production function, the initial moment when the interest rate, production and consumption all fall is slightly different. However, no significant differences are observed with respect to the steady state, so the permanence of the results can be confirmed.

The policy of a reduction of working hours causes an initial increase in unemployment and job vacancies.

The inclusion of the matching function and the distinction between active and inactive population enables information to be added. The reduction of working hours, as well as increasing the demand for work (vacancies are created in companies), also provokes an increase in the supply of labour, as shorter working days and improved expectations of finding work attract a larger proportion of the population which had, up to that moment, been inactive and now start looking for work, thus increasing the unemployment rate. It must be taken into account that 
this model does not provide for automatic entry into work; all players must go through the search period first.

If working time is reduced, vacancies open up in companies due to the increase in labour they require in the following period. The growth in the number of vacancies is inferior to the growth in searches, as the former have an assigned cost.

The combination of vacancies and searches leads to an increase in contracts. However, as the increase in contracts is not significant, the population will further intensify their search to keep contracts at a suitably high level, i.e. as matching technology leaves potential contracts uncovered (excess search and vacancies), the players, faced with radical change in working hours and a significant increase in the need for labour, exaggerate the variables of search and vacancies. In terms of possibilities for growth, searches are cheaper than vacancies, so the increase is considerably greater with respect to placement in the labour market ${ }^{12}$.

${ }^{12}$ To ensure that transition from inactivity to activity, i.e. to search, entails certain delimitating costs, a new model was constructed in which the utility function was:

$$
U\left(c_{t}, n_{t}, B_{t}, e_{t}\right)=\frac{c_{t}^{\alpha \gamma}\left(1-b B_{t}-h_{t} n_{t}-e_{t}\right)^{\gamma(1-\alpha)}}{\gamma}
$$

The only new parameter of note is $\varepsilon$, representing the costs of transition from inactivity to activity. An inactive person who decides to join in the labour market faces costs of training, professional rehabilitation, etc. The longer that person has been inactive, the higher the costs. Additionally, time-related costs such as neglecting the family, hobbies, a change of lifestyle, etc. also come into the equation.

$e_{t}$, the $\%$ of people entering the labour market for the first time in search of work, would be another parameter.

A further restriction, reflecting more explicitly all the possible situations of transition between the active and inactive state, was added to the problem of the decision of the consumer:

$$
B_{t+1}=\left(1-\psi_{2}\right)\left[B_{t}-m_{t}\right]+\left(1-\psi_{3}\right) \psi_{1} n_{t}+e_{t}
$$

The first term of the equation represents those who sought work in the previous period but who were not hired and who continue looking for work in the period $t+1$. Thus, the parameter $\psi_{2}$ is the percentage of people who pass from unemployed to inactivity group. 
After the initial period, searches, vacancies and contracts return to slightly higher levels than those of the original situation, whilst unemployment decreases to a level slightly lower than that of the starting point.

Finally, salary per hour increases as a result of the reduction in working hours, but not enough to compensate for the reduced number of working hours, so salary per working day will decrease. This result can be used to measure the welfare of households, which is clearly seen to diminish with a reduction of working hours.

\subsubsection{Dynamic of transition supposing $\kappa>\kappa^{*}$}

Many of the favourable conclusions drawn from the suppositions mentioned above, e.g. greater return on capital, greater capital, higher production and consumption levels, etc. are no longer valid when the value of productivity of working hours is modified. Others, such as higher levels of employment and participation in the labour market, remain valid (see Appendix 2, Figures 3 and 5). However, though the increase in employment is less pronounced, the increase in participation is not, so unemployment increases.

Production and consumption are destroyed, the unemployment rate grows and, as has been stated above, employment increases less when the value of $\kappa$ is high. Additionally, salary per hour diminishes in the long term due to increased labour supply.

The second term represents those who lost their job in the period $t$ and are still looking for work in the following period. $\psi_{3}$ is the percentage of people who pass from employment to inactivity group.

However, the results obtained show no qualitative difference from those presented in this section, and are therefore not included. 


\section{Conclusions}

This paper shows how, with certain modifications to a standard real business cycle (RBC) model, and with certain qualified responses in the short and long term, a policy of reduction in the number of working hours can have positive effects on activity and employment. The modifications required to bring about these results include the specification of the working day, the existence of the creation and destruction of employment and a differentiation between inactivity and unemployment.

The long-term response to a reduction in working hours essentially depends on the value assigned to the productivity of working hours and adjustment costs. In the case of capital, production, consumption and salary per hour, positive and negative responses are observed. Those variables increase with low productivity and viceversa.

Employment, vacancies and contracts always show a positive variation, though the lower the value of productivity of working time and adjustment costs, the greater this increase will be.

Labour supply would increase as a result of reducing the number of working hours, as part of the inactive population would decide to become active on account of working days being shorter and greater expectations of finding employment. Besides that, the reduction in salary per day and the consequent decline in household income also would increase labour supply. This leads to an 
increase in unemployment, accentuated in the case of a high level of productivity of working hours as this is when the creation of employment is at its lowest.

Analysis of short-term responses reveals useful forecast data on how to interpret the evidence of the effect of a reduction of working hours. Thus, although unemployment is reduced in the long-term after a reduction of working hours, it can be observed that it may increase initially before settling at lower values. Similarly, complex dynamic behaviour is also observed with respect to capital stock and consumption in certain specifications.

In short, productivity of working hours is a key factor when interpreting the effects of a reduction of working hours on the economy in general. Thus, results reveal that any measures taken to reduce the number of working hours must take into consideration the productivity levels of working hours, to ensure that the consequences of such a policy are positive not only for employment but also in all other macroeconomic variables. 


\section{Appendices}

\section{Appendix 1. Graphs of the steady state}

[ insert here figure 1]

\section{Appendix 2. Graphs with dynamic of transition ${ }^{13}$}

[ Insert here figure 2]

[ Insert here figure 3 ]

[ Insert here figure 4 ]

\section{[ Insert here figure 5 ]}

\section{Acknowledgement}

This work is supported in part by the Ministry of Minister of Science and Innovation, Spain, under the ECO2009-10398 project.

This article has been a working paper $n^{\circ} 358$ (2007) of FUNCAS (Fundación de las cajas de ahorro).

\section{References}

Andrés, J, Doménech, R, Ferri, J (2006) Price Rigidity and the Volatility of Vacancies and Unemployment, Working papers number 0601 of the Institute of International Economics, University of Valencia, Spain.

\footnotetext{
13 Note: The "y" axis shows the units of variation of the variable, whilst the " $x$ " axis shows time (measured as quarters of the year).
} 
Antolín, P (1997) Los flujos de trabajadores en el mercado de trabajo español, Papeles de Economía Española, 72, 154-167.

Blanchard, OJ, Kahn, CM (1980) The Solution of Linear Difference Models under Rational Expectations, Econometrica, 48(5), 1305-1311.

Blanchard, OJ, Diamond, P (1989) The Beveridge curve, Brookings Papers on Economic Activity, 1, 1-60.

Burda, M, Wyplosz, Ch (1994) Gross worker and job flows in Europe, European Economic Review, 38, 1287-1325.

Castillo, S, Jimeno, JF, Licandro, O (1998) Employment Segmentation, Labour Mobility and Mismatch: Spain, 1987-1993, Working Paper, FEDEA WP 98-04. Cole, HL, Rogerson, R (1999) Can the Mortensen-Pissarides matching model match the business-cycle facts?, International Economic Review, 40(4), 933959.

Contensou, F, Vranceanu, R (2000) Working Time, Edward Elgar (Ed.), Cheltenham, U.K.-Northampton, M.A. U.S.A.

Den Haan, WJ, Ramey, G, Watson, J (2000) Job Destruction and Propagation of Shocks, The American Economic Review, 90 (3), 482-498.

Dolado, JJ, García-Serrano, C, Gómez, R (1997) Creación y destrucción de empleo, Papeles de Economía Española, 72, 139-153.

Dolado, JJ, Gómez, R (1997) La relación entre vacantes y desempleo en España: Perturbaciones agregadas y de reasignación, Investigaciones Económicas XXI, (3), 441-472.

García, JI (1997) Las tasas de salida del empleo y el desempleo en España (19781993), Investigaciones Económicas, XXI (1), 29-53. 
Greenwood, J, MacDonald, GM, Zhang, GJ (1996) The cyclical behaviour of job creation and job destruction: A sectoral model, Economic Theory, 7, 95-112.

Hansen, GD (1985) Indivisible labor and the business cycle, Journal of Monetary Economics, 16 (3), 309-327.

Hornstein, A, Yuan M (1998) Can a Matching Model Explain the Long-Run Increase in Canada's Unemployment Rate?, Federal Reserve Bank of Richmond, Working Paper, 98-2.

Hosios, AJ (1990) On the efficiency of matching and related models of search and unemployment, Review of Economic Studies, 57, 279-298.

Kydland, FE, Prescott, E (1982) Time to build and aggregate fluctuations. Econometrica, 50 (6), 1345-1370.

Layard, R, Nickell S, Jackman, R (1994) El paro. Los resultados macroeconómicos y el mercado de trabajo, Ministerio de Trabajo y Seguridad Social, Spain.

Marimon, R, Scott, A (1999) Computational Methods for the Study of Dynamic Economies, In: Marimón, R., Scott, A. (Eds.), Oxford University Press.

Marimon, R, Zilibotti, F (2000) Employment and distributional effects of restricting working time, European Economic Review, 44, 1291-1326.

Merz, M (1995) Search in the labor market and the real business cycle, Journal of Monetary Economics, 36, 269-300.

Mortensen, DT, Pissarides, CA (1994) Job Creation and Job Destruction in the Theory of Unemployment, Review of Economic Studies, 61, 397-415.

Novales, A, Domínguez, E, Pérez, J, Ruiz, J (1999) Solving Nonlinear Rational Expectations Models by Eigenvalue-Eigenvector Decompositions, In: 
Marimón, R., Scott, A. (Eds.), Computational Methods for the Study of Dynamic Economies, Oxford University Press, pp. 62-92.

Novales, A (2000) The Role of Simulation Methods in Macroeconomics, Economic Review, 2 (3), 155-182.

Osuna, V, Ríos-Rull, JV (2003) Implementing the 35 hour workweek by means of overtime taxation, Review of Economic Dynamics, 6, 179-206.

Petrongolo, B, Pissarides, CA (2001) Looking into the black box: survey of the matching function, Journal of economics literature, 39, 390-431.

Pissarides, CA (1986) Unemployment and vacancies in Britain, Economic Policy 3, 499-559.

Puch L, Licandro, O (1997) Are there any special features in the Spanish business cycle?, Investigaciones Económicas, 21(2), 361-394.

Rocheteau, G (2002) Working Time Regulation in a Search Economy with Worker Moral Hazard, Journal of Public Economics, 84, 387-425.

Rogerson, R (1988) Indivisible labor, lotteries and equilibrium, Journal of Monetary Economics, 21 (1), 3-16.

Shimer, R (2005) The Cyclical Behaviour of Equilibrium Unemployment and Vacancies, The American Economic Review, 95 (1), 25-49.

Sims, CA (2001) Solving Linear Rational Expectations Models, Journal of Computational Economics, 20(1-2), 1-20.

Tripier, F (2003) Can the labor market search model explain the fluctuations of allocations of time?, Economic Modelling, 21, 131-146.

Yashiv, E (2006) Evaluating the performance of the search and matching model, European Economic Review, 50, 909-936.. 
Yashiv, E (2007) Labor Search and Matching in Macroeconomics", IZA Discussion Paper No. 2743. 